\title{
Efl undergraduate students' self-regulation in thesis writing: help-seeking and motivation-regulation
}

\author{
Concilianus Laos Mbato $^{1 *}$ Anastasia Cendra ${ }^{2 *}$ \\ ${ }^{1}$ Universitas Sanata Dharma, Yogyakarta, Indonesia, ${ }^{2}$ Universitas Sanata Dharma, Yogyakarta, Indonesia \\ ${ }^{1}$ cons@usd.ac.id, ${ }^{2}$ anelladiahp@gmail.com \\ * corresponding author
}

\section{ARTICLE INFO}

\section{Article history}

Received April 03, 2019

Revised April 25, 2019

Accepted May 20, 2019

\section{Keywords}

help-seeking

motivation-regulation

self-regulation

thesis

undergraduate

\section{ABSTRACT}

Type Undergraduate thesis writing necessitates EFL students to selfregulate themselves, particularly in overcoming the difficulties they encounter and maintaining their motivation. To date, there has been little research on EFL undergraduate students' self-regulation, helpseeking, and motivation-regulation in thesis writing, especially in Asian context. Under explanatory mixed-method framework, this research aimed to investigate how Indonesian EFL undergraduate students selfregulated their thesis writing process and to what extent their selfregulation assisted them to seek help and regulate their motivation. The results showed that the students generally demonstrated a high level of self-regulation, help-seeking, and motivation-regulation. Furthermore, it was revealed that self-regulation had a positive, significant, and moderate correlation with help-seeking ( $\mathrm{r}=.461)$, and a positive, significant, and high correlation with motivation-regulation $(\mathrm{r}=.648)$. The findings suggested that self-regulation, help-seeking, and motivation-regulation were important for students to finish their challenging undergraduate thesis. However, even when the overall measured results were good, the support from other people including from the university staff were needed, especially in cultivating students' self-regulatory mechanism. This research offers implications for the university and thesis advisors.

This is an open access article under the CC-BY-SA license.

\section{Introduction}

Writing can be described as critical skill. In its process, the writers may have particular apsects needed to deliver their idea such as background knowledge, diction mastery, critical thinking and problem solving. In adttion they are also required to tap deeper into the topic to produce a more sophisticated writing. While writing task has been considered difficult (Jahin \& Idrees, 2012, p. 11; Lee, 2017, p. 467), producing academic work challenges students to another level with many aspects to consider (Badi, 2015, p. 65). These challenges include "lack of theoretical knowledge and logical organization, lack of ability to synthesize" (Xia \& Luxin, 2012, p. 339), lack of linguistic and literacy background (Abdulkareem, 2013, p. 1553); and word selection issues (Sajid \& Siddiqui, 2015, p. 183). Moreover, in addition to students limited experience, training and understanding of 
creating an acceptable academic writing $(\mathrm{Mu}, 2010)$, academic writing also necessitates students to think critically (Abdulkareem, 2013, p. 1553; Woodward-Kron, 2002, p. 12),

Despite the aforementioned difficulties, a form of academic writing called undergraduate thesis still becomes one of the requirements for students to obtain a bachelor's degree, especially in Asian context. For students who are majoring in English language, the challenges are amplified as they are required to write in academic English, which, most of the times, is not their mother tongue (Gilmore, 2009 , p. 363). Furthermore, flexible deadlines for the students to finish their undergraduate thesis may be one of the causes of students' tendency to not complete their writing (cf. Hallberg \& Olsson, 2017, p. 14). This may lead the students to delay completing their thesis as they initially expect or, much worse, fail their study.

With these challenges at hand, it becomes essential for students to develop self-regulation in finishing their undergraduate thesis on time. Self-regulation is one's capacity to manage or control their thoughts, feelings, and actions that translate into the skills to attain a specific educational goal (Zimmerman, Bonner, \& Kovach, 1996, p. 2). The notion self-regulation has been well-researched throughout the world (e.g., Daniela, 2015; Pipattarasakul \& Singhasiri, 2018; Zeng \& Goh, 2018). Specifically, self-regulation has been found to improve students' achievement in academic writing (Hammann, 2005; Hapsari, 2015; Mehrabi, Kalantarian, \& Boshrabadi, 2016). These studies contend that highly self-regulated students tend to have better academic progress compared to those who are not.

Furthermore, to be successful in undergraduate thesis writing, students need the ability to seek help whenever necessary. The ability to seek help enables students to "avert possible failure, maintain engagement, lead to task success, and increase the likelihood of long-term mastery and autonomous learning" (Newman, 2002, p. 132). The students' self-regulation level aligns with their level of academic help-seeking (Dunn, Rakes, \& Rakes, 2014). This means that students with high level of self-regulation tend to seek help whenever they encounter problems. Self-regulated learners will know whenever they need help (Dunn et al., 2014) and they will decide when they will ask for some help, including from whom and what kind of help to ask (Finney, Barry, Horst, \& Johnston, 2018, p. 158). Students who seek help when facing a learning difficulty will have a better opportunity to succeed.

In finishing thesis writing in the midst of difficulties, it is also vital that students keep their motivation in check. Regulating motivation - the reason to do something along with how long and how much effort one is willing to do to achieve the goal (Dörnyei \& Ushioda, 2013, p. 4) - is considered essential for writing performance (Chae, 2016; Sajid \& Siddiqui, 2015), such as in finishing undergraduate thesis. Having enough motivation would enable students to have the tenacity required to finish the writing, even when the deadline is not clear. Wolters (2003) suggested that highly self-regulated students tend to have great ways to maintain their motivation in finishing their academic task (p. 189). which, in this case, is finishing an undergraduate thesis.

An extensive look to existing literature revealed that a body of empirical research has addressed to what extent self-regulation facilitates Asian learners' writing performance (e.g., Farsani, Beikmohammadi, \& Mohebbi, 2014; Hapsari, 2015; Mehrabi et al., 2016; Nasihah \& Cahyono, 2017). Nevertheless, only limited study has addressed self-regulation in thesis writing. One such study was conducted by Wagener (2017) in a western country, which focused on master's theses not the undergraduate ones. In addition, although many studies involving Asian learners have been done to address their ability to seek help during difficult times (e.g., Cheng \& Tsai, 2011; Williams \& Takaku, 2011a, 2011b) and their learning motivation (e.g., Arju, 2018; Khodadad, 2018; Surastina \& Dedi, 2018), to the best of our knowledge, little has been done to address these notions in the context of undergraduate thesis, especially in the Asian EFL learning context.

This research was conducted at the undergraduate English Education Study Program of Sanata Dharma University, Indonesia. It is important to note that in Indonesia, the teacher-centered education practices are still prevalent inside the classrooms despite the recent government efforts to promote the school and university curriculum that give prominence to student-centered learning (see Dardjowidjojo, 2001; Indah, 2017; Indah \& Kusuma, 2016; Liando, 2010, p. 119; Marcellino, 2008; Author, 2019). Sanata Dharma University, however, has been implementing student-centered learning (Universitas Sanata Dharma, 2009) where a great emphasis is put on students' development 
of knowledge and skills, commitment to seeking the truth, and being open to receiving and providing help for others. With student-oriented projects that often dominate the learning atmosphere, students are encouraged to develop as a whole human person and be responsible for their own learning. The lecturers also need to improve their awareness of "when to teach by explaining and giving examples, when to build up spirit and motivation, and when to support and supervise" (Author, 2013, p. 160). Despite the more favorable learning culture at the university, so far there has been no research pertaining to how students self-regulate their undergraduate thesis writing now that they had been used to the teacher-cantered education during their previous years of schooling.

Thus, to fill the gap and provide further literature on self-regulation, help-seeking, and motivation, especially in relation to EFL undergraduate students' thesis writing in universities around the world where thesis writing is a requirement for graduation, this research was conducted focusing on two research questions:

How do Indonesian EFL undergraduate students self-regulate themselves; particularly in helpseeking and maintaining their motivation in doing their undergraduate thesis writing?

To what extent does self-regulation facilitate Indonesian EFL undergraduate students to seek help and maintain their motivation?

\section{Self-Regulation}

Self-regulated learning is defined as "self-generated thoughts, feelings, and actions intended to attain specific educational goals" (Zimmerman, Bonner, \& Kovach, 1996, p. 2). Self-regulation allows learners, among others, to monitor and improve their learning. Zimmerman (1998) describes self-regulation as a self-fulfilling cycle involving three phases: forethought, performance, and selfreflection (p. 2). Forethought phase refers to the preparation processes to 'set the learning stage' in which students' beliefs will influence the learning process. Performance or volitional control is the processes where the learners try to maintain their concentration and performance during the learning process. Self-reflection refers to processes happen after each learning effort (Zimmerman, 1998).

Possessing self-regulation in learning can benefit learners in many ways. Zimmerman, Bonner, \& Kovach (1996) argue that self-regulation in learning allows learners to be responsible for their learning and learning strategies, which leads to overall students' advancement in learning and perceptions of self-efficacy. In addition, knowing their strengths and weaknesses enables learners to regulate their learning to achieve their academic goal (Author, 2013, p. 2). In more practical ways, the role of self-regulation for improving students' performance and achievement in learning has been well-researched (e.g., Ghasemi \& Dowlatabadi, 2018; Mega, Ronconi, \& De Beni, 2014). Some studies have also found that self-regulation enhances overall writing performance. For instance, self-regulation helps students to find enjoyment in writing (Hammann, 2005) and to perform better in writing tasks (Hacker et al., 2015) such as in helping to recall existing knowledge and review the writing (Hapsari, 2015), and in overall academic writing (Mehrabi et al., 2016).

\section{Help-Seeking}

Self-regulation means that the users are able to rcognise the possibility of difficulties and problems that they may face on writing process. It indicates that users or writers need to be able to handle those obsatacles by means of help-seeking ability. It can be one of the ways they deal with difficulties and problems during the process of achieving their academic goal (Dunn et al., 2014; Finney et al., 2018; Newman, 2002). They tend to have the help-seeking ability that allows them to realize and identify whenever they encounter difficulties and to show self-determination to remedy them by, for instance, seeking help from a more knowledgeable person (Newman, 2002, p. 132). Self-regulated learners will show some efforts to deal with difficulties - showing some social forms of learning - by displaying "personal initiative, perseverance, and adaptive skill" (Zimmerman, 2008, p. 167). 
It assumedly believed that this skill or abilty has important part on students' success. Newman (2002) contends that to be able to really implement this adaptive help-seeking, learners should possess several competencies and resources related to self-regulation, i.e. cognitive competencies such as to know when they need help; social competencies - such as to know who to approach for help; motivational resources - such as to have willingness to seek help; and contextual motivational resources - such as to know the context of the possible help-seeking (pp. 132-133). Further, Ryan \& Pintrich (1998) have summarized that there are two phases of adaptive help-seeking. First, it is important that the students have awareness that they need help. Second, the students have to decide if they should do any help-seeking (as cited in Dunn et al., 2014, p. 75).

\section{Motivation-regulation}

Failure to keep oneself motivated during the effort of attaining a certain academic goal may lead to failure in learning. Motivation is the reason why we do something, how long we are willing to do it, and how much effort we will give to achieve it (Dörnyei \& Ushioda, 2013, p. 4; Fryer \& Roger, 2017, p. 443). Motivation has been proven important for English language learners (see Muslim, 2017; Shin et al., 2018; Tanaka, 2017) and regulating it becomes very essential to enhance students' academic performance (see Mukti, 2017), especially to protect the intention to learn (Mccann \& Garcia, 1999, p. 260), and to persevere during difficult situations (Daniela, 2015, p. 2550).

Motivation to do something might differ from one learner to the others as it is affected by how much the goals mean to them, and how much they want to achieve these goals (Sansone \& Thoman, 2006, p. 1697). In short, their goals will reflect the "“what' (e.g., complete the task, score better than a standard) and the 'why' (e.g., to achieve, to have fun) of activity engagement - their extrinsic motivation" (Sansone \& Thoman, 2006, p. 1698). In addition, motivation is also affected by the way learners perceive their experience in engaging to the activity, rather than the possible outcomes. This type of activity is known as intrinsic motivation (Sansone \& Thoman, 2006, p. 1699). If the experience is interesting, the learners will get more engaged in the activity.

Research has found that self-regulated learners tend to possess "adaptive beliefs and attitudes that drive their willingness to engage and persist at academic tasks" (Wolters, 2003, p. 189), even when they encounter difficulties. These students tend to choose and implement some strategies and show determination to avoid giving up (see Mega et al., 2014, p. 121). They will exercise many strategies, such as three-factor solution related to maintaining motivation in self-regulatory process: selfefficacy enhancement, stress reducing actions, and negative-based incentives to engage to their goal more and to prevent any kinds of procrastination and early quitting (see McCann \& Garcia, 1999, pp. 273-275).

\section{Method}

\section{Research design}

As the study aimed to capture the complete understanding of the phenomenon of self-regulation on thesis writing both quantitatively and qualitatively, mixed method research was utilized (see Ary, Jacobs, Sorensen, \& Razavieh, 2010, p. 559), specifically the explanatory mixed method (Creswell, 2012 , p. 542). Quantitative research was conducted beforehand to gather general data as well as to map the respondents' self-regulation, help-seeking, and motivation-regulation level. Qualitative research was then undertaken to gain more in-depth data and to explain the phenomenon about their self-regulation, help-seeking, and motivation-regulation strategies in undergraduate thesis writing. The findings from both methods were discussed in a complementary manner.

\section{Quantitative data}

During July 2018, 102 Indonesian EFL undergraduate students of Sanata Dharma University, Indonesia completed an online three-part questionnaire, consisting of 37 statements. The questionnaire utilized Likert-type statements on the scale of 1 to 5 -with 5 represented strongly agree (SA) and 1 represented strongly disagree (SD). Online type of questionnaire was used to ease the data gathering as the respondents were able to answer the questions and submit the questionnaire online (Ary et al., 2010, p. 385). 
The first part of questionnaire was adapted from Author's self-regulation strategies (2013) and SRQ version by Erickson, Soukup, Noonan, \& McGurn (2015); the second part was adapted from help-seeking measures by Ryan \& Pintrich (1997), online help-seeking measures by Hao et al. (2016) and Karabenick's (2003) help-seeking scales; whereas the third part of the questionnaire was adapted from Mccann \& Garcia's (1999) Academic Volitional Strategy Inventory - The Three Factor Solution. To ensure its validity and reliability, the adapted questionnaire was piloted on May 2018 to 40 people who had done undergraduate thesis writing. The result showed that all items in the present questionnaire were considered valid (all rxy>0.322) and reliable, as summarized in Table 1.

Table 1. Validity and Reliability of the Questionnaire

\begin{tabular}{cccccc}
\hline Part & Aspect & N of Items & Valid & Invalid & Cronbach's Alpha \\
\hline 1 & Self-regulation & 12 & 12 & - & 0.787 \\
2 & Help-reeking & 8 & 8 & - & 0.704 \\
3 & Motivation-regulation & 12 & 12 & - & 0.808 \\
\hline
\end{tabular}

As this research focused on describing the phenomenon, the data gathered from the questionnaire were analyzed using descriptive analysis, specifically by measuring its central tendency (see Creswell, 2012, p. 184); the higher the mean indicated the higher their degree of agreement to the statement was, and vice versa. This descriptive analysis showed an overall picture of undergraduate students' strategies of self-regulation, help-seeking, and motivation-regulation in their thesis writing. In addition, correlation analyses were done to understand further how self-regulation correlated with help-seeking, and with motivation. For these correlation analyses, two alternative hypotheses were formulated as follows, where the degree of strength was determined based on Sarwono's (2009) categorization: $0=$ no correlation; $0.00-0.25=$ very weak; $0.00-0.25=$ moderate; $0.50-0.75=$ strong; $0.75-0.99=$ very strong; $1=$ perfect correlation:

a. $\mathrm{H}_{1 \mathrm{a}}=$ There was a positive and significant correlation between self-regulation and helpseeking,

b. $\mathrm{H}_{1 \mathrm{~b}}=$ There was a positive and significant correlation between self-regulation and motivation-regulation.

\section{Qualitative data}

The second part of the research was conducted by interviewing nine students involved in the research. The interviews were to help explain and explore the phenomenon deeper. The question protocols for the interviews were about how they applied self-regulation strategies, sought help when facing difficulties, and maintained their motivation in thesis writing.

The students involved in the interviews were chosen using individual purposeful sampling method (see Creswell, 2012, p. 206) based on their level of self-regulation, help-seeking, and motivation-regulation in undertaking thesis writing, which can be seen from the mapping yielded from the descriptive analysis result. Three students were chosen randomly from the comparatively highly self-regulated group, another three from moderately self-regulated group, and the other three from low self-regulated group. This was to ascertain that the qualitative data represented all students. The interviews were conducted twice for each student and were audio-recorded. The result of the interviews were transcribed and selectively coded (see Ary et al., 2010, p. 464) based on the qualitative themes. They were used to complement the quantitative data by providing further descriptions of the phenomena. Pseudonyms were used to the protect participants' confidentiality. 


\section{Findings and discussion}

\section{Findings}

In order to provide the result of this study, research findings are laid out first as the materials of discussion section.

\section{Students' self-regulation}

Table 2 presents the summary of the students' self-regulation strategies level.

Table 2. Students' Self-Regulation

\begin{tabular}{|c|c|c|c|c|c|c|c|c|}
\hline No & Aspects & SD & D & $\mathbf{N}$ & $\mathbf{A}$ & SA & Mean & $\sigma$ \\
\hline $\mathrm{A} 1$ & Planning out & 0 & 5 & 12 & 47 & 38 & 4.2 & 0.82 \\
\hline $\mathrm{A} 2$ & Setting Goal & 0 & 8 & 17 & 55 & 22 & 3.9 & 0.83 \\
\hline $\mathrm{A} 3$ & Counting tasks & 0 & 14 & 22 & 46 & 20 & 3.7 & 0.94 \\
\hline $\mathrm{A} 4$ & Estimating & 3 & 18 & 29 & 42 & 10 & 3.4 & 0.98 \\
\hline A5 & Keeping track & 0 & 10 & 23 & 54 & 15 & 3.7 & 0.83 \\
\hline A6 & Identifying all the task & 0 & 2 & 17 & 59 & 24 & 4.0 & 0.70 \\
\hline A7 & Making right choices & 0 & 3 & 15 & 71 & 13 & 3.9 & 0.62 \\
\hline $\mathrm{A} 8$ & Keeping on trying & 0 & 4 & 13 & 66 & 19 & 4.0 & 0.69 \\
\hline A9 & Evaluating progress & 1 & 10 & 23 & 51 & 17 & 3.7 & 0.89 \\
\hline $\mathrm{A} 10$ & Evaluating feelings & 0 & 1 & 11 & 45 & 45 & 4.3 & 0.70 \\
\hline A11 & Setting new goal & 0 & 3 & 16 & 64 & 19 & 4.0 & 0.68 \\
\hline A12 & Learning from mistakes & 0 & 0 & 6 & 50 & 46 & 4.4 & 0.60 \\
\hline
\end{tabular}

Table 2 shows that the students' self-regulation level was generally high. This was evident from the mean for each statement that was above the neutral number (3). For the forethought phase (statements number A1-A4), the students had already demonstrated a great 'stage-setting' for their thesis writing. Most students agreed that they did 'plan out' their thesis (A1; $\bar{x}=4.2$ ) and decided their goals in advance (A2; $\overline{\mathrm{x}}=3.9)$. This was in line with the interview result where students reported that they usually made a plan for their writing; for instance, "It's like this week, I'm going to finish this chapter and that chapter, and next week also" (Alex) or "I write down the date. I have daily target as I love to be working on schedule" (Daisy). In addition, most students showed that they considered all things to get done (A3; $\overline{\mathrm{x}}=3.7)$ and estimated how much time it would take to finish it (A4; $\overline{\mathrm{x}}=3.4$ ), indicating that they were able to prepare their writing process.

For the performance phase (A5-A8), the students were generally able to monitor their writing. The means from the statement A5 ( $\overline{\mathrm{x}}=3.7)$ and A6 $(\overline{\mathrm{x}}=4.0)$ showed that the students were able to "keep track" and "identify things to get done" related to their undergraduate thesis writing. In addition, the majority of the students showed that they could "make choices" even when they were not the most fun $(\mathrm{A} 7 ; \overline{\mathrm{x}}=3.9)$ and "keep on trying many possibilities" $(\mathrm{A} 8 ; \overline{\mathrm{x}}=4.0)$ to be successful. These quantitative results were mirrored in the interviews where most students referred back to the plan or targets they had made, such as "every time I get lazy, I try to go back to my schedule"(Daisy); while some others tried to keep the distraction away, such as by choosing to work in "a quiet room" and "turn off the phone", and "say "no' to friends asking to hang out" (Emma).

The questionnaire results showed that the students' level of self-regulation in the self-reflection phase (A9-A12) was high. This is indicated by the relatively high means of the Likert statements' response. In general, the students were able to check their performance (A9; $\bar{x}=3.7$ ) - checking whether they had accomplished their goal, examine their feeling towards their accomplishment (A10, $\overline{\mathrm{x}}=4.3$ ), set a new goal by examining how they had done (A11; $\overline{\mathrm{x}}=4.0)$, and learn from their mistakes (A12; $\overline{\mathrm{x}}=4.4$ ). Unsurprisingly, these findings were in line with the majority of the 
interviewees' response. They were able to evaluate their performance and/or feelings, know what was left to be done and set a better plan for the next round. Charles, for instance, shared that he "would be feeling a little bit disappointed if [his] target was not accomplished that day" but he then "set a better plan, usually to do more for the next round." To conclude, generally, students had demonstrated many self-regulatory strategies to plan, monitor, and evaluate their performance on thesis writing.

\section{Students' help-seeking}

Before discussing students' help-seeking, getting to know briefly about the challenges and difficulties the students experienced during the process of finishing their undergraduate thesis writing is necessary. Although not central to this research, some questions related to challenges and difficulties were asked in the beginning of the interviews. In the first round of interviews, it was confirmed that there were various difficulties faced by the students during their thesis writing. These problems arouse either from personal problems, - such as laziness or time management - or technical and language problems, - like finding the appropriate literature or appropriate vocabulary - or even problems with thesis advisor, - such as getting unclear feedback.

Despite the various problems, students had attempted to seek help. Table 3 presents the summary of their help-seeking.

Table 3. Students' Help-Seeking (HS)

\begin{tabular}{lcccccccc}
\hline No & Aspect & SD & D & N & A & SA & Mean & $\boldsymbol{\sigma}$ \\
\hline B1 & HS doesn't mean a failure & 0 & 1 & 21 & 44 & 36 & 4.1 & 0.77 \\
B2 & HS doesn't mean incapable & 2 & 7 & 20 & 41 & 32 & 3.9 & 0.98 \\
B3 & HS helps to do better & 0 & 0 & 1 & 27 & 74 & 4.7 & 0.47 \\
B4 & Asking over guessing & 1 & 0 & 8 & 35 & 58 & 4.5 & 0.73 \\
B5 & One of first things to do & 0 & 7 & 15 & 41 & 39 & 4.1 & 0.90 \\
B6 & Identifying the challenges & 0 & 4 & 18 & 51 & 29 & 4.0 & 0.79 \\
B7 & Asking lecturer(s) & 2 & 9 & 19 & 30 & 42 & 4.0 & 1.07 \\
B8 & Asking friend(s) & 0 & 4 & 9 & 46 & 43 & 4.3 & 0.78 \\
\hline
\end{tabular}

Generally, the students had great help-seeking level, including their perspective and intention towards help-seeking and their actual act of it. Drawing from the statements B1 to B3, the students generally had a positive perspective towards the act of help-seeking. When provided with statements "I do NOT feel like a failure if I need help to finish my undergraduate thesis writing" (B1; $\bar{x}=4.1)$ and "getting help in undergraduate thesis writing is NOT an admission that I am just not smart enough to do the work on my own" (B2; $\bar{x}=3.9)$, the majority of the students gave positive response to the statements. In addition, most students perceived that help-seeking helped them to do better (B3; $\overline{\mathrm{x}}=4.7$ ) This is similar to what Flo concluded when being asked about help-seeking matters, "My pride is high but not too high, so I think help-seeking is necessary. We do need that." This excerpt shows that the participants generally had a great opinion towards help-seeking.

Besides having a good perspective on help-seeking, the students showed a great intention to seek help, seen from statements B4 and B5. When facing uncertainty during the process of writing their thesis, the students preferred to "ask someone for assistance rather than guess" (B4; $\overline{\mathrm{x}}=4.5)$ and admitted that help-seeking becomes "one of the first things [they] would do" (B5; $\overline{\mathrm{x}}=4.1)$.

For the act of help-seeking, the students generally could identify their difficulties (B6; $\bar{x}=4.0)$ and sought help, from both their lecturer(s) $(\mathrm{B} 7 ; \overline{\mathrm{x}}=4.0)$ and their friends $(\mathrm{B} 8 ; \overline{\mathrm{x}}=4.3)$. These results were reflected in the interviews as well. When asked whether they could identify their difficulties, the 
majority reported they could recognize their difficulties. Charles, for example, responded, "I know if I have difficulties; I can identify them, like, I know when I am stuck." In addition, the students reported that they asked their lecturers, particularly their thesis advisor to help them, like "I would be brave enough to send him a WhatsApp chat, even though I am not sure it would be replied or just left as "read"' (Emma). In conclusion, most students demonstrated that they had a great opinion of help-seeking, high intention to seek help, and demonstrated the actual help-seeking act.

\section{Students' motivation-regulation}

Table 4 is the summary of the result of participants motivation-regulation.

Table 4. Students' Motivation-regulation

\begin{tabular}{|c|c|c|c|c|c|c|c|c|}
\hline No & Aspect & SD & D & $\mathbf{N}$ & $\mathbf{A}$ & SA & Mean & $\boldsymbol{\sigma}$ \\
\hline $\mathrm{C} 1$ & Self-talk on own ability & 0 & 1 & 5 & 36 & 60 & 4.5 & 0.64 \\
\hline $\mathrm{C} 2$ & Thinking about great outcomes & 0 & 1 & 6 & 34 & 61 & 4.5 & 0.66 \\
\hline $\mathrm{C} 3$ & Self-talk on task importance & 0 & 1 & 7 & 43 & 51 & 4.4 & 0.67 \\
\hline $\mathrm{C} 4$ & Thinking of own set-goals & 1 & 0 & 9 & 48 & 44 & 4.3 & 0.72 \\
\hline $\mathrm{C} 5$ & Giving rewards to self & 5 & 8 & 16 & 32 & 41 & 3.9 & 1.15 \\
\hline C6 & Talking to friends & 0 & 1 & 11 & 56 & 34 & 4.2 & 0.67 \\
\hline $\mathrm{C} 7$ & Trying new ways & 1 & 14 & 16 & 52 & 19 & 3.7 & 0.96 \\
\hline $\mathrm{C} 8$ & Doing relaxation & 4 & 20 & 25 & 31 & 22 & 3.5 & 1.15 \\
\hline $\mathrm{C} 9$ & Avoiding disappoint others & 2 & 2 & 12 & 36 & 50 & 4.3 & 0.89 \\
\hline $\mathrm{C} 10$ & $\begin{array}{l}\text { Remembering reason of going to } \\
\text { college }\end{array}$ & 1 & 5 & 20 & 46 & 30 & 4.0 & 0.88 \\
\hline $\mathrm{C} 11$ & Thinking of made-sacrifices & 0 & 2 & 7 & 33 & 60 & 4.5 & 0.71 \\
\hline $\mathrm{C} 12$ & Thinking of bad consequences & 1 & 1 & 17 & 42 & 41 & 4.2 & 0.82 \\
\hline
\end{tabular}

Similar to students' level of self-regulation and help-seeking, the result of the Likert-type questionnaire indicated that, in general, students' motivation-regulation strategies were high. From statements $\mathrm{C} 1$ to $\mathrm{C} 4$, it could be seen that the students generally stated that they undertook many strategies to enhance their self-efficacy. Most students reported that they did self-talk about their own ability, such as 'you can do this' $(\mathrm{C} 1 ; \overline{\mathrm{x}}=4.5)$, thought about how great they would feel once the task had been completed $(\mathrm{C} 2 ; \overline{\mathrm{x}}=4.5)$, reminded themselves that the task was important in order to graduate $(\mathrm{C} 3 ; \overline{\mathrm{x}}=4.4)$, and thought about the goals that they had set $(\mathrm{C} 4 ; \overline{\mathrm{x}}=4.3)$. In line with the questionnaire, in the interviews, the students mentioned some great efforts to enhance their selfefficacy, for instance by "telling [her]self 'C'mon, you should do this quick! You can do that" (Helen) or "saying 'keep going through to my own hell," (Flo). Here, it can be seen that the participants tell themselves motivating sentences to maintain their motivation.

To maintain their motivation, the students indicated that they did several stress reducing actions (C5-C8) to go through the challenges in writing their undergraduate thesis. With relatively high means, the majority of the students showed that they promised themselves something after having some progress (C5; $\overline{\mathrm{x}}=3.9$ ), talked to a friend and had some discussion with them (C6; $\overline{\mathrm{x}}=4.2)$, thought of interesting or different ways to do their undergraduate thesis writing $(\mathrm{C} 7 ; \overline{\mathrm{x}}=3.7)$, and used some forms of relaxation to make them concentrate better $(\mathrm{C} 8 ; \overline{\mathrm{x}}=3.5)$. Similarly, through the interview, the students revealed that they often gave themselves rewards after they achieved some amount of progress as well as some little entertainment during their writing session, like to "scroll through Instagram for a moment only to get her mind refreshed (Daisy). Similarly, Charles shared, "Before I sit down I look for a book that is not related to any theories for my thesis ... If I am feeing drowsy, I will read for several minutes and I continue writing." It indicated that he tried to keep himself motivated even when he felt bored in the thesis writing process. 
Moreover, the students indicated that they regulated their motivation by thinking of the consequence of their behavior (C9-C12), especially the negative ones. Most of the students agreed that they did not want to disappoint others $(\mathrm{C} 9 ; \overline{\mathrm{x}}=4.3)$ and remembered the reasons why they were going to college $(\mathrm{C} 10 ; \overline{\mathrm{x}}=4.0)$. In addition, they indicated that they thought of how much sacrifice they and their parents had made so far $(\mathrm{C} 11 ; \overline{\mathrm{x}}=4.5)$ as well as the bad consequences if they did not graduate on time $(\mathrm{C} 9 ; \overline{\mathrm{x}}=4.2)$. These results were parallel with the interview section, which revealed that "money" and "avoiding parental disappointment" became the biggest initial motivation for the students to finish their thesis. Overall, it is clear that the majority of students were able to regulate their motivation, be it by enhancing their self-efficacy, exercising stress-reducing actions, or thinking of possible consequences of their present actions.

\section{Self-regulation and help-seeking}

Pearson product-moment correlation was utilized to examine the relationship between selfregulation and help-seeking in undergraduate thesis writing. Table 5 is the result of the correlation analysis.

Table 5. Correlation between self-regulation and help-seeking in undergraduate thesis writing

\begin{tabular}{ccc}
\hline & & Help-Seeking \\
\cline { 3 - 3 } Self-regulation & Pearson Correlation & .461 \\
& Sig. (2-tailed) & .000 \\
& $\mathrm{~N}$ & 102 \\
& & $* *$. Correlation is significant at the 0.01 level (2-tailed). \\
\hline
\end{tabular}

As shown in table 5, the correlation between self-regulation and help-seeking in the context of undergraduate thesis writing was moderate with $\mathrm{r}=.461$, significant at 0.00 level, hence, the first alternative hypothesis (H1a) was accepted. It could be concluded that there was a positive, moderate, and significant correlation between these two notions. This quantitative correlation was supported by the qualitative data, especially in ways that the students demonstrated the importance of helpseeking in the process of regulating themselves in finishing their writing. Ian, for instance, elaborated this connection by stating, "In forethought phase, we can ask our lecturers what books we can use as references; in evaluation, maybe we can ask lecturers or friends to give us feedback and suggestions". Furthermore, Flo shared how she made the best use of reflection phase to know what needed to be improved and to inform her "when to reach out for help." Hence, from this elaboration, it can be concluded that self-regulation and help-seeking were closely related.

\section{Self-regulation and motivation-regulation}

The correlation between self-regulation and motivation-regulation in undergraduate thesis writing was also examined using Pearson product-moment correlation. Table 6 presents the result.

Table 6. Correlation between self-regulation and motivation-regulation in undergraduate thesis writing

\begin{tabular}{ccc}
\hline & & Motivation-regulation \\
Self-regulation & Pearson Correlation & $.648^{* *}$ \\
& Sig. (2-tailed) & .000 \\
& $\mathrm{~N}$ & 102 \\
\hline
\end{tabular}

**. Correlation is significant at the 0.01 level (2-tailed).

From table 6, self-regulation and motivation-regulation were correlated in $\mathrm{r}=648$, significant at 0.00 . Thus, the second alternative hypothesis ( $\mathrm{H} 1 \mathrm{~b})$ was accepted, and it was confirmed that there was a positive, high, and significant correlation between self-regulation and motivation-regulation in 
the context of undergraduate thesis writing. This finding was also evident from the interview result. The students generally acknowledged that self-regulation and motivation-regulation were highly correlated. Ian, for instance, explicitly addressed this relation, highlighting "to me, those who are self-regulated should have better motivation-regulation in doing their undergraduate thesis, and vice versa." Similarly, Beth concluded that "motivation is part of self-regulation." From these excerpts and the correlational data analysis, the students demonstrated that they were aware and agreed that self-regulation and motivation-regulation were highly related.

\section{Discussion}

Although self-regulation, help-seeking, and motivation-regulation have been popular topics for research (e.g., Hao et al., 2016; Mehrabi et al., 2016; Surastina \& Dedi, 2018), to date, only limited empirical studies have been directed to address how they are used in thesis writing, let alone the undergraduate thesis, especially in the Eastern learning contexts like Indonesia. Addressing these notions in this context would partially fill the gap and bring forth unique significance for at least three reasons: 1) undergraduate thesis writing is most likely the first time students conduct actual research (cf. Reynolds \& Thompson, 2011, p. 209); 2) working on thesis demands the students to be responsible for their own success now that their supervisor will only guide them to work independently (cf. Strauss, 2012, p. 286); 3) the concept of being independent - or self-regulated learners is not part in Indonesian learning culture (cf. Dardjowidjojo, 2001; Indah, 2017; Indah \& Kusuma, 2016; Marcellino, 2008). On this account, this study was conducted to address this matter closely, especially how Indonesian EFL undergraduate students self-regulated their thesis writing process, sought help, and maintained their motivation, as well as the relationship between selfregulation and help-seeking, and between self-regulation and motivation-regulation. Based on the quantitative and qualitative data analysis, three major findings were revealed, which will be discussed in the following paragraphs.

First, this research revealed that academic writing, in this case undergraduate thesis, presents difficulties for EFL students. It was found that students faced various challenges during the process of the thesis writing, be it technical-language, personal, or other difficulties. This finding echoes previous related studies (e.g., Badi, 2015; Chen, 2012). One possible explanation for these difficulties was that the students had to produce their work in English, which is not their mother tongue (see Gilmore, 2009, p. 363). In addition, the challenges might arise from conducting research for the first time and making the report of it (cf. Reynolds \& Thompson, 2011), where they might not have a clear idea and sufficient experience of how to write a good thesis. The difficulties may also stem from the flexible deadline (cf. Hallberg \& Olsson, 2017, p. 14), which may be equal to too much freedom of when to finish their thesis.

Second, the encouraging result of students' self-regulation, help-seeking, and motivationregulation may stem from students' learning culture in Sanata Dharma University. Data analysis results indicated that most students were able to plan, monitor, and evaluate their thesis writing process (see Zimmerman, 1998). Additionally, the students showed a positive intention towards help-seeking, great intention to do it, as well as the actual act of help-seeking whenever they really needed assistance; be it from friends, thesis advisor, or lecturers (see Newman, 2002). The students also reported many strategies to keep themselves motivated by trying to enhance their self-efficacy, doing stress reducing actions, and thinking of possible consequences to maintain their motivation (see McCann \& Garcia, 1999, pp. 273-275). These results were quite surprising, as in Eastern countries, particularly in Indonesia, teacher-centered education practices are still prevalent although the curriculum documents have stressed student-centered learning (see Dardjowidjojo, 2001; Indah, 2017; Indah \& Kusuma, 2016; Liando, 2010, p. 119; Marcellino, 2008). One possible rationale for these encouraging findings is the learning atmosphere and the supportive culture for being independent learners in Sanata Dharma University. As has been noted, student-centered approach is embraced in this university, where the lecturers generally know how and when they position themselves in the learning process (Author, 2013, p. 160). Thus, even when students had experienced and been accustomed to the teacher-centered practices during their previous years of schooling, they have likely adapted to this student-centered learning during their first years of study in this university. 
Third, self-regulation, help-seeking, and motivation-regulation are the key factors to be successful in undergraduate thesis. As this study discovered, self-regulated learners tended to have the ability to seek help and regulate their motivation, even when they encountered learning difficulties. This finding resonates well with previous studies, which argue that self-regulated learners possess the ability to seek help when the need arises (see Dunn et al., 2014; Finney et al., 2018; Newman, 2002; Zimmerman, 2008). This study is also supported by existing studies which contend that the ability of learners to self-regulate themselves align with their ability to maintain their motivation (see Daniela, 2015; Teng \& Zhang, 2018; Wolters, 1998, 2003). Hence, the finding strengthens the notion that self-regulation and motivation are closely and significantly related. While all of them bring positive impacts on students' performance (see Mehrabi et al., 2016; Mukti, 2017; Newman, 2002), it becomes essential that students implement self-regulation strategies, i.e. how they seek help when necessary and maintain their motivation to be successful in undergraduate thesis writing, an academic task, which is full of challenges particularly in EFL learning contexts.

\section{Conclusion}

Although self-regulation, help-seeking, and motivation-regulation have been popular topics for research (e.g., Hao et al., 2016; Mehrabi et al., 2016; Surastina \& Dedi, 2018), to date, only limited empirical studies have been directed to address how they are used in thesis writing, let alone the undergraduate thesis, especially in the Eastern learning contexts like Indonesia. Addressing these notions in this context would partially fill the gap and bring forth unique significance for at least three reasons: 1) undergraduate thesis writing is most likely the first time students conduct actual research (cf. Reynolds \& Thompson, 2011, p. 209); 2) working on thesis demands the students to be responsible for their own success now that their supervisor will only guide them to work independently (cf. Strauss, 2012, p. 286); 3) the concept of being independent - or self-regulated learners is not part in Indonesian learning culture (cf. Dardjowidjojo, 2001; Indah, 2017; Indah \& Kusuma, 2016; Marcellino, 2008). On this account, this study was conducted to address this matter closely, especially how Indonesian EFL undergraduate students self-regulated their thesis writing process, sought help, and maintained their motivation, as well as the relationship between selfregulation and help-seeking, and between self-regulation and motivation-regulation. Based on the quantitative and qualitative data analysis, three major findings were revealed, which will be discussed in the following paragraphs.

First, this research revealed that academic writing, in this case undergraduate thesis, presents difficulties for EFL students. It was found that students faced various challenges during the process of the thesis writing, be it technical-language, personal, or other difficulties. This finding echoes previous related studies (e.g., Badi, 2015; Chen, 2012). One possible explanation for these difficulties was that the students had to produce their work in English, which is not their mother tongue (see Gilmore, 2009, p. 363). In addition, the challenges might arise from conducting research for the first time and making the report of it (cf. Reynolds \& Thompson, 2011), where they might not have a clear idea and sufficient experience of how to write a good thesis. The difficulties may also stem from the flexible deadline (cf. Hallberg \& Olsson, 2017, p. 14), which may be equal to too much freedom of when to finish their thesis.

Second, the encouraging result of students' self-regulation, help-seeking, and motivationregulation may stem from students' learning culture in Sanata Dharma University. Data analysis results indicated that most students were able to plan, monitor, and evaluate their thesis writing process (see Zimmerman, 1998). Additionally, the students showed a positive intention towards help-seeking, great intention to do it, as well as the actual act of help-seeking whenever they really needed assistance; be it from friends, thesis advisor, or lecturers (see Newman, 2002). The students also reported many strategies to keep themselves motivated by trying to enhance their self-efficacy, doing stress reducing actions, and thinking of possible consequences to maintain their motivation (see McCann \& Garcia, 1999, pp. 273-275). These results were quite surprising, as in Eastern countries, particularly in Indonesia, teacher-centered education practices are still prevalent although the curriculum documents have stressed student-centered learning (see Dardjowidjojo, 2001; Indah, 
2017; Indah \& Kusuma, 2016; Liando, 2010, p. 119; Marcellino, 2008). One possible rationale for these encouraging findings is the learning atmosphere and the supportive culture for being independent learners in Sanata Dharma University. As has been noted, student-centered approach is embraced in this university, where the lecturers generally know how and when they position themselves in the learning process (Author, 2013, p. 160). Thus, even when students had experienced and been accustomed to the teacher-centered practices during their previous years of schooling, they have likely adapted to this student-centered learning during their first years of study in this university.

Third, self-regulation, help-seeking, and motivation-regulation are the key factors to be successful in undergraduate thesis. As this study discovered, self-regulated learners tended to have the ability to seek help and regulate their motivation, even when they encountered learning difficulties. This finding resonates well with previous studies, which argue that self-regulated learners possess the ability to seek help when the need arises (see Dunn et al., 2014; Finney et al., 2018; Newman, 2002; Zimmerman, 2008). This study is also supported by existing studies which contend that the ability of learners to self-regulate themselves align with their ability to maintain their motivation (see Daniela, 2015; Teng \& Zhang, 2018; Wolters, 1998, 2003). Hence, the finding strengthens the notion that self-regulation and motivation are closely and significantly related. While all of them bring positive impacts on students' performance (see Mehrabi et al., 2016; Mukti, 2017; Newman, 2002), it becomes essential that students implement self-regulation strategies, i.e. how they seek help when necessary and maintain their motivation to be successful in undergraduate thesis writing, an academic task, which is full of challenges particularly in EFL learning contexts.

\section{Conclusions and Implications}

This research has elucidated how Indonesian EFL undergraduate students of Sanata Dharma University, Indonesia self-regulated their thesis writing process, including how they sought help and maintained their motivation among the stream of challenges. Generally, the students demonstrated various strategies of self-regulation, help-seeking, and motivation-regulation to finish their thesis. It was also found that students who were highly self-regulated tend to seek-help and maintain their motivation better than those who were not.

This study, however, has several limitations. First, although the number of the students involved in this study was quite big $(\mathrm{N}=102)$, its findings could not be generalized to the whole context of Indonesian or Asian undergraduate students since this study was conducted specifically in the English Language Education Study Program of Sanata Dharma University. As the context was quite specific, an attempt to replicate this study to another university context, be it in Indonesia or in other Asian countries, may yield different results. Second, this study has not explored how self-regulation, help-seeking, and motivation-regulation empirically relate to students' performance in undergraduate thesis writing, especially how they can help students graduate faster and produce a good quality thesis. Hence, further researchers are encouraged to do similar studies with different contexts and discuss the relationship between the findings and students' performance in undergraduate thesis writing.

Nevertheless, this study brings forth several implications. First, self-regulation will grow in a learning environment which provides students with rich opportunity to develop their potentials wholly. Therefore, it is important that the university in general and thesis advisors in particular create the academic atmosphere that facilitates all students to develop self-regulation, help-seeking, and motivation-regulation strategies in finishing their thesis. Second, it is necessary for the students and thesis advisors to agree on certain deadlines, be it weekly or monthly as they become a tool that encourages students to keep making writing progress. Third, there is a need for programs that could familiarize students to academic English, especially for students whose mother tongue is not English so that they would be more accustomed to producing an academic writing.

\section{References}

Abdulkareem, M. N. (2013). An investigation study of academic writing problems faced by Arab postgraduate students at Universiti Teknologi Malaysia (UTM). Theory and Practice in Language Studies, 3(9), 1552-1557. https://doi.org/10.4304/tpls.3.9.1552-1557 
Arju, S. (2018). Motivation matters in adopting prewriting strategies and improving writing achievement among Banglasehi adult EFL learners. Journal of Asian and African Social Science and Humanities, 4(4), 60-75.

Ary, D., Jacobs, L. C., Sorensen, C., \& Razavieh, A. (2010). Introduction to research in education (8th ed.). Belmont: Wadsworth.

Badi, I. A. H. Al. (2015). Academic writing difficulties of ESL learners. WEI International Academic Conference Proceedings, 63-76. Retrieved from http://www.westeastinstitute.com/wp-content/uploads/2015/02/Ibtisam-Ali-Hassan-Al-Badifull-Paper.pdf

Chae, S. E. (2016). Importance of ongoing motivation for EFL writers' performance: The Journal of Asia TEFL, 13(4), 280-293. https://doi.org/http://dx.doi.org/10.18823/asiatefl.2016.13.4.3.280 The

Chen, X. (2012). The effect of subconscious learning vs performance goals on performance on a complex task. University of Toronto. Retrieved from https://tspace.library.utoronto.ca/bitstream/1807/33949/1/Chen_Xiao_201211_PhD_thesis.pd f

Cheng, K. H., \& Tsai, C. C. (2011). An investigation of Taiwan University students' perceptions of online academic help seeking, and their web-based learning self-efficacy. Internet and Higher Education, 14(3), 150-157. https://doi.org/10.1016/j.iheduc.2011.04.002

Creswell, J. W. (2012). Educational research: Planning, conducting, and evaluating quantitative and qualitative research. Educational Research (4th ed., Vol. 4). Boston: Pearson. https://doi.org/10.1017/CBO9781107415324.004

Daniela, P. (2015). The relationship between self-regulation, motivation and performance at secondary school students. Procedia - Social and Behavioral Sciences, 191, 2549-2553. https://doi.org/10.1016/j.sbspro.2015.04.410

Dardjowidjojo, S. (2001). Cultural Constraints in the Implementation of Learner Autonomy. Journal of Southest Asian Education, 2(2), 309-322.

Dörnyei, Z., \& Ushioda, E. (2013). Teaching and researching motivation (2nd ed.). New York: Routledge.

Dunn, K. E., Rakes, G. C., \& Rakes, T. A. (2014). Influence of academic self-regulation, critical thinking, and age on online graduate students' academic help-seeking. Distance Education, 35(1), 75-89. https://doi.org/10.1080/01587919.2014.891426

Erickson, G. A. S., Soukup, J. H., Noonan, P. M., \& McGurn, L. (2015). Self-Regulation Questionnaire. Univeristy of Kansas: Center for Research Learning.

Farsani, M. A., Beikmohammadi, M., \& Mohebbi, A. (2014). Self-regulated learning, goal-oriented learning, and academic writing performance of undergraduate Iranian EFL learners. The Electronic Journal for English as a Second Language, 18(2), 1-19.

Finney, S. J., Barry, C. L., Horst, S. J., \& Johnston, M. M. (2018). Exploring profiles of academic help seeking: A mixture modeling approach. Learning and Individual Differences, 61, 158171. https://doi.org/10.1016/j.lindif.2017.11.011

Fryer, M., \& Roger, P. (2017). Identifying with the L2 self: study abroad experiences of Japanese English language learners. The Journal of Asia TEFL, 14(3), 443-463. 
https://doi.org/http://dx.doi.org/10.18823/asiatefl.2017.14.3.5.443 The

Ghasemi, A. A., \& Dowlatabadi, H. R. (2018). Investigating the role of task value, surface/deep learning strategies, and higher order thinking in predicting self-regulation and language achievement. The Journal of Asia TEFL, 15(3), 664-681.

Gilmore, A. (2009). Using online corpora to develop students' writing skills. ELT Journal, 63(4), 363-372. https://doi.org/10.1093/elt/ccn056

Hacker, D. J., Dole, J. A., Ferguson, M., Adamson, S., Roundy, L., \& Scarpulla, L. (2015). The short-term and maintenance effects of self-regulated strategy development in writing for middle school students. Reading \& Writing Quarterly: Overcoming Learning Difficulties, 122. https://doi.org/10.1080/10573569.2013.869775

Hallberg, D., \& Olsson, U. (2017). Self-regulated learning in students' thesis writing. International Journal of Teaching \& Education, 5(1), 13-24. https://doi.org/10.20472/TE.2017.5.1.002

Hammann, L. (2005). Self-regulation in academic writing tasks. International Journal of Teaching and Learning in Higher Education, 17(1), 15-26. Retrieved from http://www.isestl.org/ijtlhe/

Hao, Q., Barnes, B., Wright, E., \& Branch, R. M. (2016). The influence of achievement goals on online help seeking of computer science students. British Journal of Educational Technology, 48(6), 1273-1283. https://doi.org/10.1111/bjet.12499

Hapsari. (2015). A learner's self-regulated learning in writing. Indonesian Journal of English Education, 2(2), 120-131. https://doi.org/10.15408/ijee.v2i2.3085

Indah, R. N. (2017). Critical thinking, writing performance and topic familiarity of Indonesian EFL learners. Journal of Language Teaching and Research, 8(2), 229-236. https://doi.org/10.17507/jltr.0802.04

Indah, R. N., \& Kusuma, A. W. (2016). Factors affecting the development of critical thinking of indonesian learners of English language. Journal Of Humanities And Social Science, 21(6), 86-94.

Jahin, J. H., \& Idrees, M. W. (2012). EFL major student teachers' writing proficiency and attitudes towards learning English. Umm Al-Qura University Journal of Educational \& Psychologic Sciences, 4(1), 10-72. Retrieved from http://www.ibrarian.net/navon/paper/EFL_Major_Student_Teachers_Writing_Proficiency_a. pdf?paperid=20381401

Karabenick, S. A. (2003). Seeking help in large college classes: A person-centered approach. Contemporary Educational Psychology, 28(1), 37-58. https://doi.org/10.1016/S0361476X(02)00012-7

Khodadad, M. (2018). The relation of language learning strategy use with self-efficacy, motivation, and English language schievement. Journal of Modern Languages, 28, 1-20.

Lee, H. (2017). The effects of university English writing classes focusing on self and peer review on learner autonomy. The Journal of Asia TEFL, 14(3), 464-481. https://doi.org/http://dx.doi.org/10.18823/asiatefl.2017.14.3.6.464 The

Liando, N. V. F. (2010). Students' vs. teachers' perspectives on best teacher characteristics in EFL classrooms. TEFLIN Journal, 21(2), 118-136. https://doi.org/10.15639/TEFLINJOURNAL.V21I2/118-136

Marcellino, M. (2008). English language teaching in Indonesia: A continuous challenge in education and cultural diversity. TEFLIN Journal, 19(1), 57-69. 
Author, C. L. (2013). Facilitating EFL learners' self-regulation in reading: Implementing a metacognitive approach in an Indonesian higher education context. ePublications@SCU. Southern Cross University.

Author, C. L. (2019). Indonesian EFL learners' critical thinking in reading: Bridging the gap between declarative, procedural and conditional knowledge. Humaniora, 31(1), 92-101. https://doi.org/https://doi.org/10.22146/jh.v31i1.37295

McCann, E. J., \& Garcia, T. (1999). Maintaining motivation and regulating emotion: Measuring individual differences in academic volitional strategies *. Learning and Individual Differences, 11(3), 259-279.

Mega, C., Ronconi, L., \& De Beni, R. (2014). What makes a good student? How emotions, selfregulated learning, and motivation contribute to academic achievement. Journal of Educational Psychology, 106(1), 121-131. https://doi.org/10.1037/a0033546

Mehrabi, M., Kalantarian, S. R., \& Boshrabadi, A. M. (2016). The interplay between selfregulation strategies, academic writing achievement and gender in an Iranian L2 context. Journal of Applied Linguistics and Language Research, 3(2), 230-239. Retrieved from http://www.jallr.com/index.php/JALLR/article/viewFile/288/pdf288

Mu, C. (2010). I only cited some of his words": The dilemma of EFL students and their perceptions of plagiarism in academic writing. The Journal of Asia TEFL, 7(4), 103-132.

Mukti, T. W. P. (2017). The role of students' motivational self-regulation in structure III. Language and Language Teaching, 20(2), 116-126. https://doi.org/doi.org/10.24071/1lt.2017.200205

Muslim, A. B. (2017). Heritage narratives, motivation to learn english and the development of national identity: An Indonesian perspective. The Journal of Asia TEFL, 14(3), 414-429. https://doi.org/http://dx.doi.org/10.18823/asiatefl.2017.14.3.3.414 The

Nasihah, M., \& Cahyono, B. Y. (2017). Language learning strategies, motivation, and writing achievement of Indonesian EFL students. Arab World English Journal, 8(1), 250-263. https://doi.org/https://dx.doi.org/10.24093/awej/vol8no1.18

Newman, R. S. (2002). How self-regulated learners cope with academic difficulty: The role of adaptive help seeking. Theory Into Practice, 41(2), 132-138. https://doi.org/10.1207/s15430421tip4102

Pipattarasakul, P., \& Singhasiri, W. (2018). Metastrategies employed by science and engineering. The Journal of Asia TEFL, 15(1), 66-81. https://doi.org/http://dx.doi.org/10.18823/asiatefl.2018.15.1.5.66 The

Reynolds, J. A., \& Thompson, R. J. (2011). Want to improve undergraduate thesis writing? Engage students and their faculty readers in scientific peer review. CBE Life Sciences Education, 10(2), 209-215. https://doi.org/10.1187/cbe.10-10-0127

Ryan, A. M., \& Pintrich, P. R. (1997). "Should I ask for help?" The role of motivation and attitudes in adolescents' help seeking in math class. Journal of Educational Psychology, 89(2), 329341. https://doi.org/10.1037//0022-0663.89.2.329

Sajid, M., \& Siddiqui, J. A. (2015). Lack of academic writing skills in English language at higher education level in Pakistan: causes, effects and remedies. International Journal of Language and Linguistics, 2(4), 174-186.

Sansone, C., \& Thoman, D. B. (2006). Maintaining activity engagement: Individual differences in 
the process of self-regulating motivation. Journal of Personality, 74(6), 1697-1720. https://doi.org/10.1111/j.1467-6494.2006.00425.x

Sarwono, J. (2009). Statistik itu mudah: Panduan lengkap untuk belajar komputasi statistik menggunakan SPSS 16. Yogyakarta: Penerbit Universitas Atma Jaya Yogyakarta.

Shin, S., Song, H., Choi, H., Myung-hwan, H., Lee, H., Lee, Y. M. C., ... Lee, H.-K. (2018). Why we do and what we do: The experience of good english. The Journal of Asia TEFL, 15(1), 130-147. https://doi.org/http://dx.doi.org/10.18823/asiatefl.2018.15.1.9.130 The

Strauss, P. (2012). "The English is not the same": Challenges in thesis writing for second language speakers of English, 17(3), 283-294.

Surastina, \& Dedi, F. S. O. D. (2018). Examining academic writing motivation of prospective Indonesian language teachers using exploratory factor analysis. International Journal of Instruction, 11(2), 15-24. https://doi.org/10.12973/iji.2018.1122a

Tanaka, M. (2017). Factors affecting motivation for short in-class extensive reading. The Journal of Asia TEFL, 14(1), 98-113. https://doi.org/http://dx.doi.org/10.18823/asiatefl.2017.14.1.7.98 The

Teng, L. S., \& Zhang, L. J. (2018). Effects of motivational regulation strategies on writing performance: A mediation model of self-regulated learning of writing in English as a second/foreign language. Metacognition and Learning, 13(2), 213-240. https://doi.org/10.1007/s11409-017-9171-4

Universitas Sanata Dharma. Statuta Universitas Sanata Dharma (2009).

Wagener, B. (2017). The importance of affects, self-regulation and relationships in the writing of a master's thesis. Teaching in Higher Education, 1-16. https://doi.org/10.1080/13562517.2017.1379480

Williams, J. D., \& Takaku, S. (2011a). Gender, writing self-efficacy, and help seeking. International Journal of Business, Humanities and Technology, 1(3), 46-54.

Williams, J. D., \& Takaku, S. (2011b). Help seeking, self-efficacy, and writing performance among college students. Journal of Writing Research, 3(1), 1-18. https://doi.org/http://dx.doi.org/10.17239/jowr- 2011.03.01.1

Wolters, C. A. (1998). Self-regulated learning and college students' regulation of motivation. Journal of Educational Psychology, 90(2), 224-235. https://doi.org/10.1037/00220663.90.2.224

Wolters, C. A. (2003). Regulation of motivation: Evaluating an underemphasized aspect of selfregulated learning. Educational Psychologist, 38(4), 189-205. https://doi.org/10.1207/S15326985EP3804_1

Woodward-Kron, R. (2002). Disciplinary learning through writing: An investigation into the writing of undergraduate education students. University of Wollongong Thesis Collection. Retrieved from http://ro.uow.edu.au/theses/1776

Xia, W., \& Luxin, Y. (2012). Problems and strategies in learning to write a thesis proposal: A study of six M.A. students in a TEFL rogram. Chinese Journal of Applied Linguistics, 35(3), 324341. https://doi.org/10.1515/cjal-2012-0024

Zeng, Y., \& Goh, C. C. M. (2018). A self-regulated learning approach to extensive listening and its impact on listening achievement and metacognitive awareness. Studies in Second Language Learning and Teaching, 8(2), 193-218. https://doi.org/10.14746/ssllt.2018.8.2.2

Zimmerman, B. J. (1998). Developing self-fullfilling cycles of academic regulation: An analysis of 
examplary instructional models. In D. H. Schunk \& B. J. Zimmerman (Eds.), Self-regulated learning: From teaching to self-reflective practice (pp. 1-19). New York: The Guilford Press.

Zimmerman, B. J. (2008). Investigating self-regulation and motivation: Historical background, methodological developments, and future prospects. American Educational Research Journal, 45(1), 166-183. https://doi.org/10.3102/0002831207312909

Zimmerman, B. J., Bonner, S., \& Kovach, R. (1996). Developing self-regulated learners: Beyond achievement to self-efficacy. Washington DC: American Psychological Association. 